\title{
THE ROLE OF CULTURE IN THE DEVELOPMENT OF GLOBAL E-COMMERCE SYSTEMS
}

\author{
Jill Slay $^{1}$ and Gerald Quirchmayr ${ }^{1,2}$ \\ ${ }^{1}$ University of South Australia, School of Computer and Information Science, Mawson Lakes \\ Campus, Mawson Lakes, SA 5095, Australia, [Gerald.Quirchmayr|Jill.Slay]@UniSA.edu.au
}

${ }^{2}$ Universität Wien, Institut für Informatik und Wirtschaftsinformatik, Liebiggasse 4/4-6, A-1010 Wien, Austria, Gerald.Quirchmayr@univie.ac.at

\begin{abstract}
This paper examines e-commerce systems as complex distributed information systems, using Kline's multidisciplinary perspectives and soft system methodologies. It contends that culture, which can be viewed from both an organisational and an anthropological perspective, is an important system variable and argues that the application of models and theories from anthropology can be helpful in the understanding of the development of shared meaning and sense making within such a system. This analysis provides a means by which cross-cultural collaboration and trust in Electronic Commerce can be developed.
\end{abstract}

Key words: electronic commerce and corporate culture, global electronic commerce systems, formalization.

\section{INTRODUCTION}

Society has become increasingly dependent on the development of large and complex software and hardware systems. With moves towards globalisation in many spheres, and with a continued emphasis on developing

\footnotetext{
The original version of this chapter was revised: The copyright line was incorrect. This has been corrected. The Erratum to this chapter is available at DOI: 10.1007/978-0-387-35604-4_20 
international collaboration on a wide scale, whether in e-commerce or egovernment, Internet mediated activity has been growing incredibly fast.

Much of the research into the development and application of such distributed information systems has been founded on existing theoretical frameworks. Business disciplines such as marketing and law have easily influenced the electronic world but, in order to understand the complexity of cross-cultural activity there is a growing interest in the integration of anthropological perspectives with the modelling, and thus development of, complex distributed systems.

The research objective here is to first develop an informal model of the role of culture in such complex distributed systems and from there to develop a formal understanding of the role of culture in an E-Commerce system. Following Checkland [1], these systems are conceived as complex socio-technical systems since they can be idealised as open systems that depend on the technology, the thought processes of the people involved, and the organisational environment.

\section{RESEARCH IN CULTURE AND INFORMATION SYSTEMS}

The use of soft systems methodologies allow us to identify internetmediated distributed systems as complex socio-technical systems since they can be idealised as open systems which depend on the technology, the sentiments of the members, and the organisational environment [1]. Although the system is organised to focus on a primary task (e-commerce transactions and communications) this cannot be separated from the environment and the social factors, including cultural ones [1].

Checkland also notes that a reasonable method for gaining an understanding of such a system is to produce an overview of the system from several perspectives. It allows us to incorporate subjective and objective impressions of the system into a bricolage, a rich picture, which allows us to include the human agents, the problems, conflicts and other seemingly "soft" aspects of the system so as to determine the areas, which need improvement ([11], [12]). Informal models are made of problem areas within a system to allow new conceptual models to be built and compared and evaluated against the problem in the rich picture. Formalisation of these conceptual models allows for solution of the problems within the system.

We turn to Kline [8] who also gives us an understanding of how to derive credible perspectives on the complex system under examination. He 
maintains that three foundational perspectives of a multifaceted and hierarchical system are a synoptic, a piecewise and a structural perspective.

A structural view is one that provides details of how a particular system fits together within its hierarchy and provides information on the relationship between local and global effects within the system .

A piecewise view is one that looks at the smallest portions of a system that might be relevant in providing information to aid in the solution of any particular problem.

A synoptic view is an overview, which extracts, synthesises and thus maps a desired property of the system.

\section{DEFINITIONS OF CULTURE}

Culture is a concept that is often discussed in academic literature. Before attempting an analysis of the role of culture in complex systems is important to gain a working definition from appropriate literature $[2,5,15]$. The definition of culture is often understood differently by researchers in different fields as they carry out their studies. Definitions of 'culture' have originated in two general domains :

- anthropology and ethnography

- political empowerment

\subsection{Anthropology}

Classic understandings of culture found in early anthropological literature see culture as the 'knowledge, belief, law, morals, customs' [15], which are passed on from one generation to another within a particular society or group of people. Anthropologists of this generation (at the end of the $19^{\text {th }}$ Century) were expected to examine a 'civilisation' and produce a taxonomy with categories such as weapons, myths, rites, and ceremonies.

Their work however demonstrated the study of culture as an art rather than a science, and failed in its attempts to produce anthropological and positivist scientific laws regarding culture from fieldwork. Although they wanted to keep interpretation separate from pure fact, a common early perspective on the study of culture was that it consisted largely of identifying particular human behaviour, and interpreting the underlying beliefs causing the specific behaviour.

'Civilisations' and enterprises have become much more complex during the twentieth century, and anthropological concepts of culture have been applied in many fields of study, including nursing, studies of policing and 
factory work. The definition of 'culture' has thus been extended, and described in many complex and diverse ways. There is still considerable debate concerning 'the sacred heart of ethnography, the culture concept' [4]. Postmodernists and deconstructivists also have problems with the concept of discrete and finite cultures and an 'incredulity towards metanarratives' [4]. Others regard the concept of culture as something left over from a colonising era [4].

The definition of culture that is most commonly found in the literature of science and engineering [2] is that of Clifford Geertz who indicates that "The concept of culture I espouse ... is essentially a semiotic one. Believing.. that man is an animal suspended in webs of significance he has spun, I take culture to be those webs, and the analysis of it to be therefore not an experimental science in search of law but an interpretive one in search of meaning. [5]

Geertz' definition is one which proposes that a person's knowledge of his or her world, is essentially mediated by signs, and it is the structure of these signs which establishes reality for an individual or a group [15].

\subsection{Political Empowerment}

There is a link also between this notion of culture and multiculturalism, and the ensuing effect of multiculturalism on society. Giroux's understanding of culture in this domain is one that is widely accepted in education and is that "culture is reduced to a type of monumentalism and ... is organised around the process of transmission and the practice of moral and political regulation" [6]

Within the literature of science education, especially when dealing with issues of multiculturalism, the definitions of culture become blurred. Some researchers adopt a critical perspective on the explication of culture from anthropology and Geertz's [5] 'webs of significance' become interwoven with the politicised 'straightjacket' of the system, as expressed by Giroux [6].

\subsection{WORLD VIEW}

The term 'world view' [2] has two different connotations in English. The first has a philosophical meaning and involves a person's concepts of human existence and reality; the second is an individual's picture of the world that he or she lives in. The term 'world view' as used in anthropology refers to the 'culturally-dependent, implicit, fundamental organisations of the mind [2] It therefore carries the concept of "sensemaking" - if we understand a 
world view then we can also understand how the people within that particular group make sense of the world around them.

Kearney's [7] model of world view presumes a logical and structural integration of presuppositions within any individual and therefore the model is known as a logico-structural one. He then identifies seven logicostructural categories contained within a given individual's world view:

- The Other

- Classification

- Causality

- Relationship

- Self

- Time \& Space

These categories serve as a framework for analysis of a world view. Kearney [7, p.65] draws the parallel between these factors of an individual world view and the categories a doctor uses for the diagnosis of a patient's disease. In order to determine the world view of an individual, his or her understanding of the seven categories of Other, Self, Time \& Space, etc., need to be identified and integrated to produce a picture of the complete world view.

\section{KLINE'S ANALYSIS OF COMPLEX SYSTEMS}

Kline's hypothesis, [8]is that at least three views are needed for a reasonably good understanding of hierarchically structured systems with interfaces of mutual constraint: synoptic, piecewise and structural.

\subsection{Structural View}

Arguably, the most common type of architecture view is the structural view in which a system is depicted as a set of inter-related elements. Examples include:

- the contents lists of books and papers;

- the taxonomies used by biologists to categorise forms of life;

- the high-level designs of software systems;

- the graphs used by mathematicians to depict systems as networks of nodes and inter-connecting arcs;

- the blue-prints used by the architects of buildings and engineers in general; 
- the master-plans used by business strategists to depict the interrelationships of other subsidiary plans;

- the organisation charts used to depict the authority/responsibility structures in institutions.

\subsection{Piecewise View}

Another common view is the piecewise view that depicts the smallest relevant parts of a system for a particular problem. Examples include:

- the detailed wiring diagrams produced by electronic and electrical engineers that show the smallest components of the devices with which they are concerned and the way that they are inter-connected;

- the detailed design drawings produced by mechanical engineers that show the smallest components of the devices with which they are concerned and the way that they are inter-connected;

- the musical scores used by composers to depict the notes to be played by the instruments in orchestras;

- the ingredients lists of recipes;

- the inventories of repositories.

\subsection{Synoptic View}

A less common type of architecture view is the synoptic view. Synoptic views treat systems as an atomic entities or wholes. They selectively emphasise characteristics of the system that are deemed to be salient in a given context and suppress (or omit) information that is not pertinent in these respects. Examples include:

- the synoptic weather charts used in television and newspaper weather reports. These are perhaps the examples of synoptic views that are most commonly encountered in everyday life;

- "black-box" system diagrams that emphasise the inputs and outputs to a system (the black-box) and the relationships between the inputs and outputs resulting from the action of that system. Such diagrams do not depict how the transformation from input to output takes place;

- topographical, political, climatic, demographic etc. maps.

When considering the possibilities of multicultural enterprises or institutional cultures or international expansion (and thus forming a system of systems), it is important to recognise therefore that an understanding of the dominant culture of each sub-system is necessary before the beginning a cooperative venture. 
Anthropological techniques whether viewed as scientific ones, as Tyler did, or the more artistic and interpretive ones, allow for the creation of ethnography which can provide the synoptic view of the enterprise. An understanding of the local political situation and local worldviews, from modern and historical sources, provide different perspectives on the effect of culture on the human activity system

\section{DISCUSSION - APPLICATION IN E-COMMERCE}

In considering an Electronic Commerce system it is apparent that a structural view of a particular company's e-commerce system would include a top-level view of the elements within that company and the particular hierarchical way in which the elements relate to each other. A piecewise view of the e-commerce system would give the details of the smallest relevant pieces involved in the system, including the hardware, software and human activity which comprised the system. A synoptic view, and one which emphasized the role of culture within the system, would focus on the role of culture within the system, the inputs and outputs that were affected by cultural issues.

Consider the situation where a Chinese company, which is already trading online, seeks to expand into the Australian market and also become involved with sub-contractors in Australia. The major cultural issues might include:

- management styles

- attitude towards privacy in IT usage

- attitude towards IT security

- buyer's trust in online purchasing

- staff belief systems (are they "scientific" in their decision making?)

\subsection{Structural View}

A structural view may be constructed where we imagine the Chinese company A and its links with its Australian partners, company B and C. Since the trading is electronic then we can assume the environment in which it takes place is cross-cultural, neither totally Chinese nor Australia 


\subsection{Piecewise View}

A piecewise view of the system would give a comprehensive layout and specification of all hardware, software and staff needed to allow effective internal and external communication by Companies $\mathrm{A}, \mathrm{B}$ and $\mathrm{C}$ in cyberspace.

\subsection{A Synoptic View}

As has been stated, culture is a semiotic concept which implies that the system is dependent on the meaning which each human agent within the system gives to important features of the system. Worldview theory gives an opportunity to examine the system from the individal human operator upwards and to determine his or her particular response to:

- The Other

- Classification

- Causality

- Relationship

- Self

- Time \& Space

With this understanding it is therefore possible to predict the response of an individual to a particular stimulus or change and to begin to have an understanding of the effect of this change on the system dynamics. A synoptic view that allows only for the effect of culture might examine the differences of an individual, and thus the group, within Company $\mathrm{A}$ in their interactions with Company $\mathrm{B}$ and Company $\mathrm{C}$ individually and the issues that Company A, Company B and Company $\mathrm{C}$ face as a they cooperate in their relationships within cyberspace (another foreign culture to them).

World View theory uses universal "cognitive categories" to describe people. These have been discussed above but, taking the first, Relationship, as an example, it is possible thus to use an analysis which "classifies" individuals from Company $\mathrm{A}, \mathrm{B}$ and $\mathrm{C}$ within cyberspace and develop a series of attributes to represent the cultural factors under consideration.

Examples of Relationship that have impact on e-commerce and information systems include:

- Management style

○ By directive

- By budget 
○ By objective

○ By exception

It is also possible to consider cultural attitudes towards Causality and examine:

- Belief systems

○ Religious

○ Political

- Scientific / Rational

The Other could also be examined, with cultural attitude to the natural world being the object of consideration, with:

- Natural World

- Western scientific

- New Age

So Company A might be depicted as:

Belief $(A$, management by directive $)=\langle .1, .3\rangle$ Belief $(A$, management by objective $)=\langle .8, .9\rangle$ Belief $(A$, management by budget $)=\langle .7, .8\rangle$

Belief $(A$, religious belief system $)=\langle .3, .5\rangle$ Belief $(A$, political belief system $)=\langle .1, .2\rangle$ Belief $(A$, rational belief system $)=<7, .9>$

Belief $(A$, western scientific view on natural world $)=\langle .7, .9\rangle$ Belief $(A$, new age view on natural world $)=\langle .1,2>$

If a similar analysis of Company B and Company $\mathrm{C}$ were carried out and a diagnosis were to be made using similar cognitive characteristics, it might be found that Company B was made up of people whose belief system was much more homogenously religious and political and with animistic views of the natural world, for example, and with a management approach which was largely by objective. If it were known that Company $\mathrm{C}$ displayed another quite different profile then management problems and for example, system usage and security issues, could be anticipated well in advance. With 
this kind of qualitative information, useful decisions as to the nature of possible business problems could be made well before the commencement of a joint venture in e-commerce.

In an ideal case crisp values (i.e. a percentage) could identify to which degree an attribute value holds true. In a real world scenario an approximation is usually all that is available for such criteria [15].

To set up a successful virtual enterprise venture between companies A, B and $C$, their cultural value base needs to be clarified and possible conflicts have to be identified. Dealing with this conflict potential is an issue for which different approaches have been developed. Taking the statistical average or the intersection of crisp sets and limiting business operations to this area would mean to follow the traditional risk-averse business model [10]. However, there are more advanced concepts than this way of conflict avoidance, namely conflict resolution and viewpoint integration ([12], [11]).

\section{TOWARDS A FORMALIZATION OF THE MODEL}

A formalization of the model will most probably result in an approach consisting of two steps. In the first step possible conflicts are identified, in the second step, they are resolved following a hierarchy of commonly agreed values and beliefs. The more of these values are shared, the easier the conflict resolution becomes. International law with its underlying peer to peer concept, can serve as model.

The first step, the identification of possible conflict situations, can be handled with Rough Sets, from which rules are created that identify sets of situations representing agreements, disagreements and unresolved situations. In case of clear agreement and clear disagreement, it is obvious that certain areas of business or certain business operations should be entered or should not be entered. The interesting issue is unresolved situations. This is where conflict resolution and viewpoint integration become interesting. If only partial agreement can be reached, i.e. a only a partial overlap in the belief system is identified, there are basically two ways to go: split the task between the partners according to the values prevailing in the company, or if a splitting into two separate tasks is impossible, bring in a third partner who can make up for the missing contribution. Viewpoint integration can also mean that two different partially contradicting views can exist with local consistency (for each of the business partners), but not overall consistency ([16], [17]). 


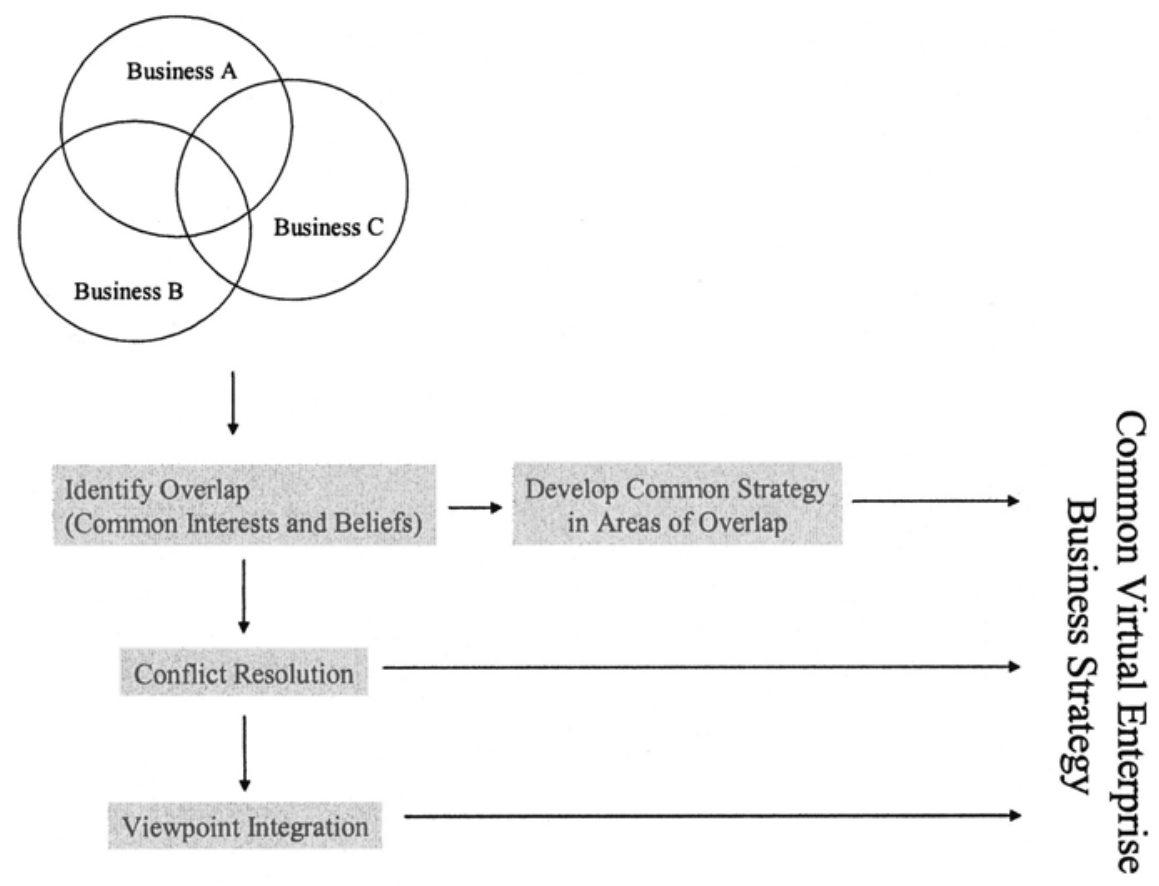

Figure 1: The Structural Model

As the degree of overlap does also depend on the degree of belief in the knowledge of the business partners the value system, crisp values are rather the exception than the rule. Establishing upper and lower boundaries of an interval is easier than identifying exact percentages. That is why Rough Sets are a promising way for getting a viable estimate. It will not be as exact as an estimate based on traditional statistical methods, but will on therefore also be less likely to produce a wrong estimate.

Rules identified in the areas of overlap lead to a common business strategy, rules outside this overlap will be treated in two ways: If they cause no conflict, they are fine anyway. If they cause a conflict, a conflict resolution mechanism will be employed. If it leads to a result, the problem is also solved, if not, rules leading to a conflict can only be applied locally, i.e. in an area not covered by the joint operation. The formal background required for implementing this procedure can be found in [10], [11], and [12].

Maintaining the rule base and coping with cultural change in the participating institutions that affects the whole virtual enterprise requires an evolutionary model, comparable to the one described in [13]. In order to 
become operational this evolutionary model then needs to be integrated with a layered model of virtual enterprise organization, such as the one presented in [14]. The approach discussed in this paper can therefore conceptually be viewed as culturally aware extension of the layered model for supporting VE communications developed by Tagg and Quirchmayr [14].

\section{CONCLUSION}

The inability to deal with cultural issues is one of the major shortcomings of today's global electronic commerce infrastructure. That is why in this paper we have focused on approaches towards integrating cultural aspects in e-commerce systems. We have also demonstrated a way of formalizing these approaches and shown how the formalization can be based on sound and already proven models. In the last part of the paper we have proposed a road towards implementation derived from work previously carried out by the authors in other contexts and by integrating the work of other researchers in the institution.

\section{REFERENCES}

[1] P. Checkland, Systems Thinking, Systems Practice, Chichester, UK: Wiley, 1981.

[2] W. Cobern, "World view theory and science education research", NARST Monograph No 3, Manhattan, KS: National Association for Research in Science Teaching, 1991.

[3] W. Cobern, World view - reality as viewed by students: A synopsis of methodology, Annual meeting of the National Association for Research in Science Teaching, San Francisco, CA. 1995.

[4] J. Fabian, Time and the other: How anthropology makes its object, New York: Columbia University Press, 1983.

[5] C. Geertz, The interpretation of cultures, New York: Basic Books, 1973.

[6] H Giroux, Curriculum discourse as postmodern critical practice, Geelong, Victoria, Australia: Deakin University Press, 1990.

[7] M Kearney, World View, Novalto, CA: Chandler \& Sharp, 1984.

[8] S. J Kline, Conceptual Foundations for Multidisciplinary Thinking, Stanford, CA, USA: Stanford University Press, 1999

[9] E H Schein, Organizational Culture and Leadership, Jossey-Bass, 1997.

[10] A. de Korvin, G. Quirchmayr, S. Hashemi, R. Kleyle. Rule Extraction Using Rough Sets when Membership Values are Intervals. Proc. of the 9th International Confernce on Database and Expert Systems Applications (DEXA 98), Vienna, Austria, August, 1998 
[11]A. Finkelstein, J. Kramer, and M. Goedicke (1990), ViewPoint Oriented Software Development, Proceedings of International Workshop on Software Engineering and its Applications, Toulouse, France, December 1990.

[12] K. Hipel and D.B. Meister, "Conflict Analysis Methodology for Modelling Coalition in Multilateral Negotiations", Information and Decision Technologies, Vol. 19, No. 2, pp. 85-103, 1994

[13] G. Quirchmayr, J. Slay. Identifying Emerging Web-Communication Patterns Between Government and Citizens, in Proceedings of 12th International Conference (DEXA 2001), 3-7 September 2001, Munich, Germany

[14] R. Tagg, G. Quirchmayr. Towards an Interconnection Model for Evolution of Shared Workflows in a Virtual Enterprise, in Proceedings of Third Int. Conference on Information Integration and Web-Based Applications and Services, September 2001, Linz, Austria

[15] B. Kosko, "Fuzzy Thinking : The New Science of Fuzzy Logic", ISBN 0-78686021-X.

[16] S.A. Kripke, Naming and Necessity, Harvard University Press, Cambridge (Mass.) 1972 (reprint 1999), ISBN 0-674-59845-8,

[17] M. Baaz and G. Quirchmayr, The Application of Multiple Valued Logic in Supporting Legal Decision Making, in The IEEE 17th International Symposium on Multiple-Valued Logic, p. 243 ff., IEEE, Washington 1987 